\title{
Conselhos Municipais do Idoso e Representações Sociais de seus Conselheiros
}

Janaína da Silva Gonçalves Fernandes Centro Universitário FIEO, SP, Brasil.
Márcia Siqueira de Andrade

Centro Universitário FIEO, SP, Brasil.

Resumo: Todo percurso brasileiro, para favorecer políticas públicas de proteção e integração do idoso na sociedade, aparentemente apresenta uma lacuna. O objetivo desta pesquisa foi identificar as representações sociais de conselheiros sobre o conselho municipal do idoso. Participaram 36 integrantes de Conselhos Municipais dos Direitos do Idoso (CMDI) de quatro municípios da região oeste da grande São Paulo, de ambos os sexos, com idades entre 20 e 80 anos. Para a coleta de dados utilizou-se questionário sociodemográfico e entrevista semiestruturada. Os dados foram analisados pela Classificação Hierárquica Descendente, com o apoio do software Interface de R pour analyses Multidimensionnelles de Textes et de Questionnaires (IRAMUTEQ). Os resultados apontaram que a maior preocupação dos participantes diz respeito às violações dos direitos dos idosos. Ainda foi possível identificar que suas representações estão pautadas na dinâmica e nas diretrizes para atuação no CMDI. Considerou-se que apesar dos conselheiros do CMDI terem como função fiscalizar e regularizar políticas públicas efetivas para a população idosa, eles deparam-se com dificuldades para exercer plenamente a função de conselheiro.

Palavras-chave: Políticas Públicas, Representação Social, Velhice.

\section{Municipal Councils of the Elderly and Social Representations of their Counselors}

Abstract: Every Brazilian story, to favor public policies of protection and integration of the elderly in society, apparently presents a gap. The objective of this research was to identify the social representations of counselors on the municipal council of the elderly. Thirty - six members of Municipal Councils for the Rights of the Elderly (CMDI) participated in four municipalities in the western region of Greater São Paulo, both sexes, aged between 20 and 80 years. For data collection, a sociodemographic questionnaire and a semi-structured interview were used. Data were analyzed by the Descending Hierarchical Classification, with the support of the Interface Software of $R$ pour analyses Multidimensionnelles de Textes et de Questionnaires (IRAMUTEQ). The results pointed out that the participants' main concern was related to violations of the rights of the elderly. It was still possible to identify that their representations are based on the dynamics and the guidelines for action in the CMDI. It was considered that although the CMDI advisors have the function of supervising and regularizing effective public policies for the elderly population, they find it difficult to exercise the full capacity of the counselor.

Keywords: Public Policy, Social Representation, Old Age. 


\title{
Consejos Municipales de las Personas Mayores y Representaciones Sociales de sus Consejeros
}

\begin{abstract}
Resumen:Aparentemente, cada camino brasileño, a favor de políticas públicas para la protección e integración de las personas mayores en la sociedad, aparentemente tiene una brecha. El objetivo de esta investigación fue identificar las representaciones sociales de los consejeros sobre el consejo municipal de ancianos. Participaron 36 miembros de los Consejos Municipales de Derechos de los Ancianos (CMDI) de cuatro municipios de la región occidental de la gran São Paulo, de ambos sexos, con edades comprendidas entre 20 y 80 años. Para la recolección de datos, se utilizó un cuestionario sociodemográfico y entrevistas semiestructuradas. Los datos se analizaron mediante la Clasificación Jerárquica Descendente, respaldada por el software Interface de R pour analyses Multidimensionnelles de Textes et de Questionnaires (IRAMUTEQ). Los resultados indicaron que la mayor preocupación de los participantes se refiere a las violaciones de los derechos de las personas mayores. También fue posible identificar que sus representaciones se basan en la dinámica y las pautas para actuar en CMDI. Se consideró que, aunque los consejeros de CMDI tienen la función de supervisar y regularizar políticas públicas efectivas para la población de edad avanzada, enfrentan dificultades para ejercer plenamente la función de consejero.
\end{abstract}

Palabras clave: Políticas Públicas, Representación Social, La vejez.

\section{Introdução}

A Organização das Nações Unidas (Organização das Nações Unidas [ONU], 2014) destaca que o aumento do número de idosos em nível mundial tem sido constante, ultrapassando o número de crianças menores de 5 anos e devendo atingir $21 \%$ do total da população global até o ano de 2050. O Brasil ocupa o $4^{\circ}$ lugar na população de idosos na América Latina (Global Agewatch Index, 2013). Segundo o Instituto Brasileiro de Geografia e Estatística (Instituto Brasileiro de Geografia e Estatística [IBGE], 2013), a projeção é que a população de idosos passe a $13,8 \%$ do total de brasileiros em 2020 e 33,7\% em 2060.

No Brasil, apesar da inserção de questões sobre a velhice na Constituição Federal de 1988, somente em 1994 foi instituída a Política Nacional do Idoso (PNI), Lei $\mathrm{n}^{\circ}$ 8.842/1994, com o objetivo de assegurar os direitos sociais do idoso, fomentando condições para promover sua autonomia, integração e participação efetiva na sociedade. A PNI dispõe sobre os direitos dos brasileiros com idade igual ou superior a 60 anos e declara que o processo de envelhecimento diz respeito à sociedade em geral, devendo ser objeto de conhecimento e informação para todos (Muller \& Parada, 2013).
Com a Lei $\mathrm{n}^{\circ} 8.842 / 1994$ foram criados o Conselho Nacional, Conselhos Estaduais e Municipais dos Direitos do Idoso, órgãos responsáveis pela coordenação geral da PNI e que consiste na união da sociedade civil com o poder público em prol da pessoa idosa. $\mathrm{O}$ Conselho Municipal dos Direitos do Idoso (CMDI) é um órgão colegiado, de caráter consultivo, deliberativo, controlador e fiscalizador da política de defesa dos direitos do idoso. O CMDI é composto de forma paritária por representantes de organizações não governamentais do município, diretamente ligadas à defesa ou atendimento ao idoso, legalmente constituídas e eleitas por representantes do Poder Público Municipal, escolhidos e nomeados pelo Prefeito, todos os conselheiros para mandato de dois anos. $\mathrm{O}$ CDMI pode atuar, também, incentivando e apoiando a realização de eventos, estudos e pesquisas no campo da promoção, proteção e defesa dos direitos do idoso, recebendo denúncias de desrespeito a esses direitos e adotando as medidas cabíveis (Muller \& Parada, 2013).

No que diz respeito à sociedade, o maior desafio para oportunizar o envelhecimento ativo está associado a reconhecer o fio que reúne todos os domínios políticos relevantes, tais como: emprego, pensões, reformas, saúde, cidadania, proteção social, inclusão social, transporte e educação. De tal modo, Walker 
(2002) aponta que muitos idosos enfrentam limitações biológicas e às vezes o desenvolvimento econômico, político e social que estrutura as sociedades inibe e impede que os indivíduos permaneçam ativos, como por exemplo, deficiências nos sistemas de aposentadoria, mercado de trabalho, saúde, e de proteção social, bem como a fragilidade dos núcleos familiares, exclusão social, ageismo cultural e na cultura de consumo midiática. Estas questões implicam a necessidade de políticas públicas específicas, discutidas pela sociedade e garantidas pelo Estado.

Como as representações sociais são definidas como um conjunto de informações, crenças, opiniões e atitudes a um determinado objeto, isto é, um conjunto de elementos organizado e estruturado (Moscovici, 2012), se tornam necessários estudos que busquem identificar os elementos que possivelmente promovem a conservação, as transformações e a consolidação de certas representações sociais, não somente nos níveis psicológico e relacional (cognitivo), mas também no nível das políticas públicas (social) (Xavier, 2002).

A Teoria das Representações Sociais é compreendida como o estudo científico do senso comum, uma vez que o senso comum se apresenta como uma forma de conhecimento específico, não sendo uma forma falha de conhecimento científico. Ela varia, de acordo com o contexto de relações sociais no qual está inserido, dando sentido à realidade dos grupos sociais e influenciando em suas visões de mundo. O processo de construção das representações sociais contribui para compreensão de como elas interferem na vida cotidiana dos indivíduos ou grupos, de modo simultâneo, por meio dos processos de objetivação e ancoragem. Logo, as representações sociais surgem justamente na inter-relação dos universos, no qual o conhecimento científico articula-se aos saberes popular e ao senso comum, dando lugar a uma nova forma de saber, de acordo com a reelaboração do saber por parte dos grupos sociais, bem como dos meios que possuem para tal (Moscovici, 2012).

Almeida, Santos e Trindade (2000) explicam que o pensamento e a ação podem estar relacionados, ou seja, entre o que se diz e o que se faz pode corresponder a natureza da relação entre a representação e a prática social. E compreender esta relação entre a prática e representação é fundamental para compreender como são construídas as representações sociais, e respectivamente como elas orientam as práticas sociais dos indivíduos. Neste sentido, as práticas sociais podem ser definidas como um conjunto de ações que podem se apresentar no formato de uma organização, encadeada e padronizada.

Partindo do exposto, o objetivo desta pesquisa é identificar o conteúdo das representações sociais daqueles que atuam nos Conselhos Municipais dos Direitos do Idoso, uma vez que compete a eles na prática, submeter, opinar, discutir, debater e decidir, por meio de seu voto, temas que envolvam os direitos do público idoso. Com esta pesquisa espera-se contribuir para a discussão de políticas públicas para a preparação para velhice no Brasil.

\section{Método}

Trata-se de uma pesquisa de abordagem qualitativa com delineamento descritivo e explicativo realizada em CMDIs localizados em quatro municípios da região oeste da grande São Paulo. Todos estes municípios apresentam perfil urbano e Índice de Desenvolvimento Humano Municipal (IDHM) alto. Porém, a dimensão que mais contribui para o IDHM destes municípios é longevidade, seguida da renda e por última educação (Atlas Brasil, 2013).

\section{Participantes}

O estudo contou com uma amostra de conveniência, em que participaram 36 conselheiros com idade entre 20 e 80 anos, sendo 25 membros titulares e 11 suplentes. Como critério de inclusão foi selecionado os participantes que apresentaram maior frequência nas reuniões plenárias mensais do CMDI. Em relação à representatividade 22 participantes são do poder público e 14 da sociedade civil. Quanto ao tempo de atuação no CMDI, 15 tinham menos de um ano, 7 dois anos, 12 três anos e 2 dez anos. Em relação a esta variável parece que há preocupação com a renovação dos membros do CMDI.

Em relação às variáveis sociodemográficas tem-se o seguinte: a) Sexo: maioria de mulheres $(\mathrm{N}=$ 24) e 12 homens; b) Estado civil: 17 se declaram casados, sete solteiros, sete divorciados e cinco viúvos; c) Escolaridade: a maioria declarou Ensino Superior completo $(\mathrm{N}=20)$; seis com Ensino Médio completo e 10 com Ensino Fundamental incompleto; d) Faixa etária: a maioria está abaixo de 60 anos $(66,6 \%)$, idade a partir da qual o indivíduo é considerado idoso, sendo 
assim distribuído: 20 a 29 anos $(\mathrm{N}=4), 30$ a $39(\mathrm{~N}=5)$, 40 a $49(\mathrm{~N}=9), 50$ a $59(\mathrm{~N}=6), 60$ a $69(\mathrm{~N}=4), 70$ a 79 $(\mathrm{N}=7)$, e 80 a $89(\mathrm{~N}=1)$.

\section{Instrumentos}

A pesquisa utilizou os seguintes instrumentos para coleta dos dados: a) Questionário sociodemográfico; b) Entrevista semiestruturada, audiogravada, desenvolvida a partir de algumas questões: Qual sua maior preocupação com o idoso do município? Você tem conhecimento do Estatuto do Idoso? Quais artigos ou conteúdo consideram mais importantes? e/ou conhece os direitos das pessoas idosas? O que considera ser um conselheiro municipal do CMDI? Como vê sua atuação enquanto conselheiro? Como os idosos estão articulados para participarem no CMDI? Participam da tomada de decisões em relação à política do idoso? O CMDI realiza atividades para os demais idosos do município? Quais os desafios ao CMDI para a implantação da política para o idoso? O que o Poder Público poderia fazer para implantar ou aperfeiçoar o atendimento ao indivíduo que envelhece?

\section{Procedimentos de coleta de dados e éticos}

A pesquisa foi aprovada pelo Comitê de Ética em Pesquisa da Instituição promotora. Inicialmente foi mantido um contato prévio com os CMDI para solicitação de autorização para realização da pesquisa. Durante reuniões plenárias dos CMDI foi explicado aos conselheiros os objetivos e procedimentos da pesquisa. Em dia, hora e local reservado e previamente agendado, foram aplicados individualmente questionário sociodemográfico e entrevista semiestruturada. Assegurou-se sigilo e anonimato de todos participantes.

\section{Procedimentos de análises dos dados}

Os dados coletados foram analisados pela Classificação Hierárquica Descendente (CHD) com o apoio do software Interface de R pour analyses Multidimensionnelles de Textes et de Questionnaires (IRAMUTEQ) versão 0.7. A CHD é apresentada na forma de uma árvore denominada dendrograma, indicando os eixos dos discursos, as classes lexicais e suas oposições. As classes são apresentadas com as palavras que as compõem e seus respectivos qui-quadrados $\left(\mathrm{x}^{2}\right)$. O programa ainda apresenta os trechos dos discursos em que as palavras classificadas foram ditas (Camargo \& Justo, 2013). Desse modo, a presente abordagem permite a identificação de possíveis elementos representacionais no conteúdo das respostas.

\section{Resultados}

Foram analisadas 36 entrevistas a partir de dois corpora monotemáticos. Cada corpus trouxe questões que abordaram os seguintes temas: "preocupação com o idoso", e "políticas públicas para população idosa".

\section{Preocupação com o idoso}

No procedimento de CHD, o software distribuiu 83 seguimentos de textos (ST) em cinco classes, e destes $14(83,13 \%)$ foram retidos da análise $(\mathrm{N}=69)$, ou seja, houve boa consistência e adequação do conteúdo submetido para análise. Esta análise obteve 2732 ocorrências de palavras, que após 543 lematizações resultou em 319 palavras distintas, com frequência média de 32,91 por ST. A Figura 1 apresenta o dendrograma com a repartição das classes, que foram categorizadas conforme inferências semânticas.

Na primeira partição, o corpus dividiu-se em dois subcorpora, onde o primeiro eixo sugere "serviços de orientação" para os idosos (classes 1), destacando sobre a preocupação de orientar os idosos para obterem conhecimento de seus direitos. Consequentemente, o segundo eixo apresenta as demais classes (2, 3, 4 e 5) que abordam os conflitos relacionados à violação dos direitos dos idosos, e ainda apontam os responsáveis para a garantia destes direitos. Logo, a segunda partição deu origem à classe 5 categorizada como "Conflitos familiares". A terceira partição originou a classe 2 categorizada como "Saúde e transporte" que se repartiu nas classes 3 ("responsabilidade civil") e classe 4 ("papel do município").

Cada classe comporta um conjunto de ST, que se relacionam pelo vocabulário utilizado, remetendo a campos semânticos específicos. Os resultados do dendrograma serão descritos obedecendo à ordem de distribuição das classes.

"Serviços de orientação" (Classe 1): representa $18,84 \%$ dos ST retidos para análise $(\mathrm{N}=13)$. Corresponde principalmente aos depoimentos de conselheiros com idade de 40 anos, com o Ensino Médio completo, representantes dos órgãos públicos da área da defesa civil. Os conteúdos que compõem esta classe sinalizam sobre a necessidade de encaminhar os idosos para medidas de 


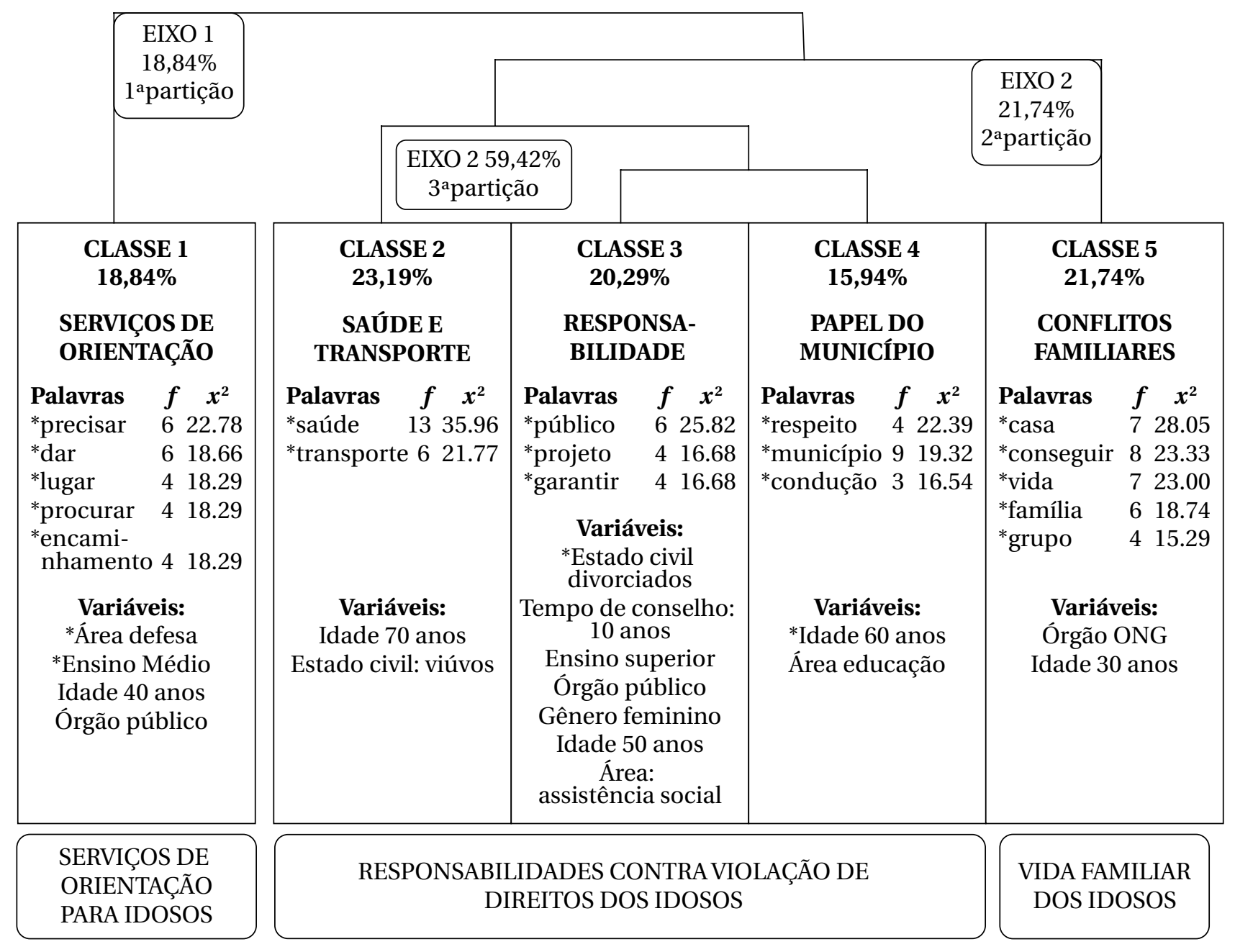

* nível de significância da palavra ou variável com a classe $\mathrm{p}<0,0005$.

f: frequência; $x^{2}$ : qui-quadrado; ONG: Organização não governamental.

Figura 1

Dendrograma da Classificação Hierárquica Descendente do corpus “Preocupação com o Idoso”. Elaborado a partir dos resultados do software IRaMuTeQ.

cuidados protetivos. Esse apontamento é exemplificado no trecho a seguir: "Não é somente orientar, pois às vezes o idoso não sabe onde ou quem procurar e se tiver um local que oferece um encaminhamento para o problema dele fica mais fácil para expor sua necessidade" (conselheira de 40 anos, ensino médio, delegacia do idoso).

"Saúde e transporte" (Classe 2): corresponde a maior classe, uma vez que representa $23,19 \%$ dos ST retidos para análise $(\mathrm{N}=16)$. Corresponde principalmente aos depoimentos de conselheiros com idade de 70 anos e viúvos. Os conteúdos que compõem esta classe apresentam discursos que reivindicam a melhoria dos sistemas de saúde e transporte públicos. De tal modo, a fala seguinte demonstra que o teste- munho da violação destes direitos norteiam os conselheiros idosos a buscarem meios de defender os seus pares: "Já pedi auxílio para levar um memorando para os postos de saúde, pois lá o idoso é maltratado, como também tenho visto isto ocorrer nos sistemas de transporte público" (conselheiro de 70 anos, ensino fundamental, sindicato dos aposentados).

Os depoimentos ainda trazem a problematização da violação dos direitos ao transporte público, abordando a questão das dificuldades de mobilidade urbana que afligem o público que apresentam algum tipo de dificuldade na mobilidade física para ter acesso ao direito garantido por lei. $\mathrm{O}$ trecho seguinte apresenta a necessidade de efetivação da legislação, no âmbito 
de garantir o acesso ao transporte direcionado para os direitos de quaisquer seres humanos em situação de fragilidade móbil: "Melhorar o transporte para os idosos, mulheres grávidas ou com crianças de colo, possibilitar para o cadeirante utilizar o elevador para subir e descer do ônibus é mais um pedido que estou fazendo" (conselheiro de 70 anos, ensino fundamental, usuário).

"Responsabilidade civil" (Classe 3): representa $20,29 \%$ dos ST retidos para análise $(\mathrm{N}=14)$. Corresponde principalmente aos depoimentos de conselheiros com idade de 50 anos, do sexo feminino, divorciados, com ensino superior completo, moradores fora do município do CMDI que atuam representantes de órgãos públicos, na área da assistência social, e com mais de 11 anos de atuação no CMDI. Os conteúdos que compõem esta classe atribuem ao público civil à responsabilidade de garantir os direitos dos idosos. Esta concepção pode ser observada no trecho a seguir: "Garantir políticas públicas voltadas para os direitos desse segmento. Parece ser um segmento esquecido, pois a sociedade não dá tanta importância para o idoso, porque já está velho, não tem mais produtividade" (conselheira de 40 anos, ensino superior, assistência social).

Neste sentido, o depoimento a seguir atribui ao próprio idoso a responsabilidade de mobilizar ações que eliminem o estereótipo de pouco interesse dos mesmos nas causas sociais e, que ainda promovam evoluções em prol da população idosa: "Haja vista que na Conferência Nacional do Idoso, tinha o mínimo de representatividade de idosos. Quanto menos pessoas participando, menor o número de pessoas brigando para garantir esses direitos" (conselheira de 50 anos, ensino superior, assistência social).

"Papel do município" (Classe 4): corresponde a menor classe, uma vez que representa $15,94 \%$ dos ST retidos para análise $(\mathrm{N}=11)$. Corresponde principalmente aos depoimentos de conselheiros com idade de 60 anos e representantes de órgãos da educação. Os conteúdos que compõem esta classe debatem as falhas do município, no âmbito de atendimento público, para garantir os direitos dos idosos. O depoimento seguinte apresenta a falta de instrumentos de atendimento ao público de idoso em situação de abandono ou fragilidade dos laços familiares: "Em relação às Instituições de Longa Permanência, não é oferecido um acolhimento de abrigo moradia para idosos do município, no âmbito de Sistema de Governo, apenas em sistemas privados" (conselheira de 30 anos, ensino superior, assistência social).
Os depoimentos dos conselheiros participantes retomam o tema do transporte público, que no caso da presente pesquisa, paralela a questão da saúde pública foi a problematização mais citada na presente pesquisa. Desta vez, o problema é atribuído à falta de respeito dos sistemas de transporte público do município para efetivação da garantia deste direito. O depoimento a seguir exemplifica esta situação: "Eu já briguei várias vezes, pois não temos o direito de andar numa condução. Nós temos o sistema de transporte do município que é para nos servir, mas tem ônibus que não carrega idoso" (conselheiro de 60 anos, ensino fundamental, usuário).

Conflitos familiares (Classe 5): corresponde a segunda maior classe, uma vez que representa $21,74 \%$ dos ST retidos para análise $(\mathrm{N}=15)$. Corresponde principalmente aos depoimentos de conselheiros com idade de 30 anos representantes de organizações não governamentais (ONG) que prestam atendimento para o público idoso. Os conteúdos que compõem esta classe problematizam os conflitos que fragilizam o bem-estar dos idosos no cotidiano familiar. Essa problematização é exemplificada no trecho a seguir: "Eu fico preocupada com o idoso que é mais fragilizado, que fica isolado porque não consegue sair de casa, pois a família trabalha o dia inteiro e não consegue acompanhar o idoso" (conselheira de 30 anos, Ensino superior, assistência social).

A violação dos direitos dos idosos no que diz respeito ao abuso financeiro por parte dos familiares é outra questão que preocupa os conselheiros participantes da pesquisa, como pode ser observado no trecho seguinte: "O idoso não tem garantia dos direitos dentro da própria casa, pois sofrem diversos abusos até por questões financeiras. Dentro do parâmetro da agressão essa é uma missão que temos com o idoso e não conseguimos ser resolutivos" (conselheira de 50 anos, ensino superior, saúde pública).

\section{Políticas públicas para população idosa}

No procedimento de CHD, o software distribuiu 624 ST em cinco classes, e destes 125 (79,97\%) foram retidos da análise ( $\mathrm{N}=499)$, ou seja, houve boa consistência e adequação do conteúdo submetido para análise. Esta análise obteve 22.152 ocorrências de palavras, que após 1.750 lematizações resultou em 1195 palavras distintas, com frequência média de 35,50 por ST. A Figura 2 apresenta o dendrograma com a repartição das classes, que foram categorizadas conforme inferências semânticas. 


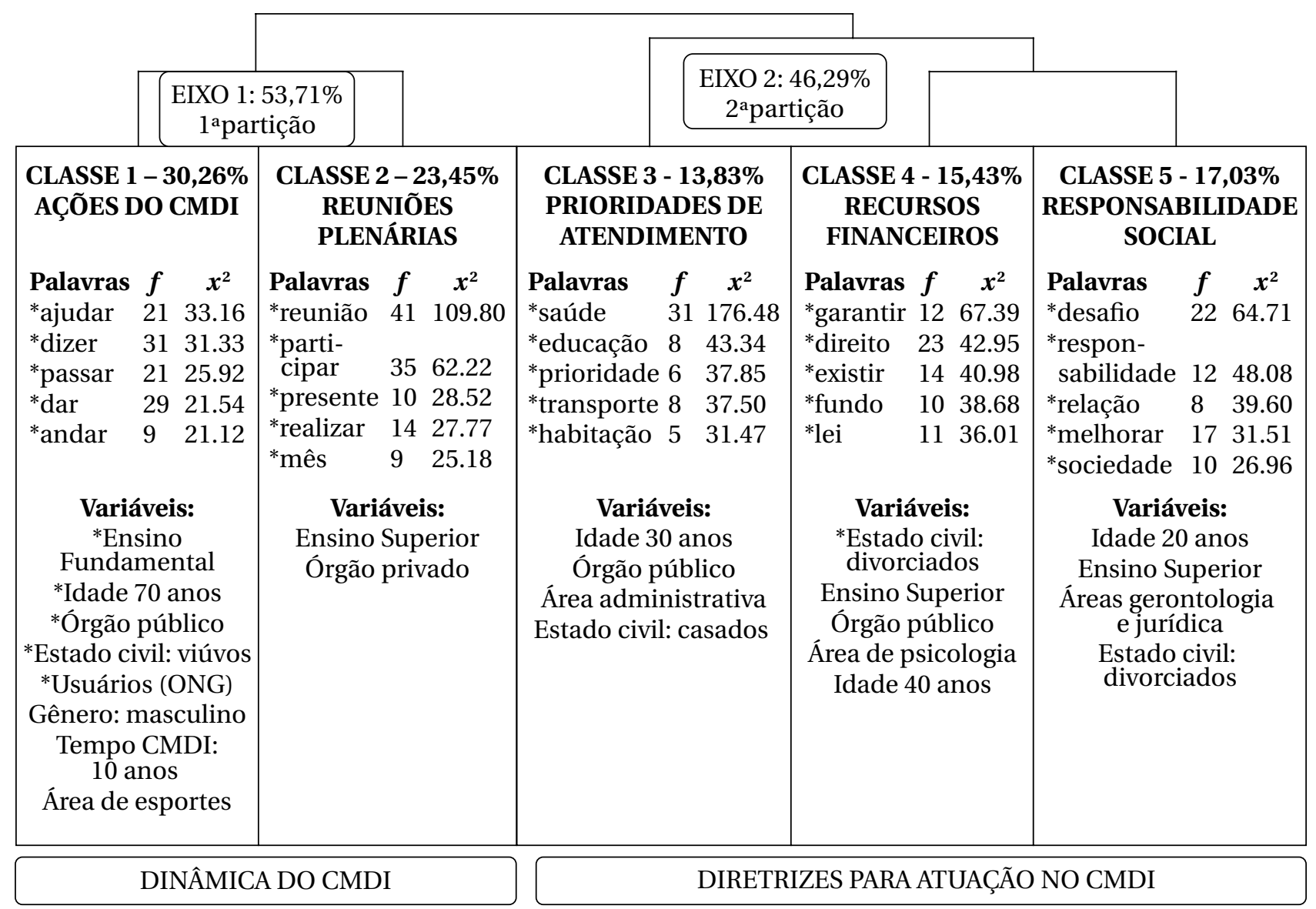

* nível de significância da palavra ou variável com a classe $\mathrm{p}<0,0005$.

f: frequência; $x^{2}$ : qui-quadrado; ONG: Organizações não governamentais: CMDI: Conselhos Municipais dos Direitos do Idoso.

Figura 2

Dendrograma da Classificação Hierárquica Descendente do corpus "Políticas públicas para a população idosa". Elaborado a partir dos resultados do software IRaMuTeQ.

Na primeira partição, o corpus dividiu-se em dois subcorpora, originando no primeiro eixo as classes 1 (“Ações do CMDI”) e a classe 2 ("Reuniões plenárias") que caracterizam a dinâmica do CMDI. O segundo eixo apresenta nas classes (3, 4 e 5), as diretrizes elencadas pelos conselheiros que dificultam ou facilitam a atuação destes atores no CMDI. A segunda partição originou a classe 3 categorizada como "Prioridades de atendimento", que se repartiu nas classes 4 ("recursos financeiros") e classe 5 ("responsabilidade social”).

Cada classe comporta um conjunto de ST, que se relacionam pelo vocabulário utilizado, remetendo a campos semânticos específicos. Os resultados do dendrograma serão descritos obedecendo à distribuição das classes.

"Ações do CMDI" (Classe 1): corresponde a maior classe, uma vez que representa $30,26 \%$ dos ST retidos para análise $(\mathrm{N}=151)$. Esta classe corresponde princi- palmente aos depoimentos de conselheiros do gênero masculino, com idade de 70 anos, viúvos, com Ensino Fundamental completo. Esta amostra ainda caracteriza representantes da secretaria de esportes, usuários de órgãos públicos e ONG de atendimento ao público idoso, e que atuam há mais de 10 anos no CMDI. De tal modo, percebe-se maior heterogeneidade, do público que caracteriza esta classe. Os conteúdos que compõem esta classe apresentam as motivações e dificuldades que regem a dinâmica do CMDI. O trecho a seguir possibilita a reflexão sobre as motivações que justificam o trabalho dos conselheiros junto ao CMDI: "O trabalho de conselheiro, eu faço de coração, porque sou uma pessoa que gosta de ajudar os outros. Sou testemunha que os membros do CMDI trabalham em prol dos idosos e trabalham bem" (conselheiro de 70 anos, ensino fundamental, sindicato dos aposentados). 
Os conteúdos que compõem esta classe também apontam as dificuldades, ou melhor, dizer a impossibilidade de os conselheiros exercerem suas funções no CMDI de modo exclusivo. Essa reflexão pode ser exemplificada a partir dos depoimentos seguintes: "Infelizmente eu não sou só do conselho do idoso. Eu tenho muitas atribuições, pois participo de mais 4 conselhos, mas acredito que tenho feito a minha parte" (conselheira de 40 anos, ensino superior, assistência social). "Nós temos outras atividades, mas procuro sempre que possível contribuir para que tenhamos um bom resultado. Infelizmente não estamos sempre à disposição" (conselheira de 40 anos, ensino médio, corpo de bombeiro).

"Reuniões plenárias" (Classe 2): corresponde a segunda maior classe, uma vez que representa $23,45 \%$ dos ST retidos para análise $(\mathrm{N}=117)$. Corresponde principalmente aos depoimentos de conselheiros com Ensino Superior completo, representantes de órgãos privados de caráter filantrópico. Os conteúdos que compõem esta classe apresentam como funciona a dinâmica das reuniões do CMDI. O seguimento de texto seguinte explica este processo: "Ficar lendo a ata durante as reuniões leva todos a dormirem e os usuários acham muito chato, e muitos não querem ir à outra reunião. Teria que ser mais atrativa, não sei como seria isso" (conselheira de 30 anos, ensino superior, assistência social).

É possível observar a insatisfação individual e coletiva da dinâmica das reuniões do CMDI na fala anterior. Existe a preocupação de aproximar os conselheiros para suas funções dentro do CMDI, e simultaneamente despertar os seus interesses em relação à causa da população idosa. Para isto, apontam a necessidade de divulgação e a reflexão sobre outros modos de conduzir estas reuniões. Por outro lado, o trecho a seguir aponta um cenário reflexivo diferenciado, com o desenvolvimento de outros caminhos: "Não adianta exigirmos que o idoso venha até nós, porque isto é uma questão cultural que deve ser trabalhada, e assim o ideal é nós irmos até onde ele está" (conselheira de 50 anos, ensino superior, assistência social).

"Prioridades de atendimento" (Classe 3): corresponde a menor classe, uma vez que representa $13,83 \%$ dos ST retidos para análise $(\mathrm{N}=69)$. Esta classe corresponde principalmente aos depoimentos de conselheiros de 30 anos, casados, representantes de órgãos públicos na área administrativa. Os conteúdos que compõem esta classe abordam as prioridades de aten- dimento para a população idosa que mais preocupam os participantes desta pesquisa. O trecho seguinte exemplifica o setor da saúde como maior prioridade nos discursos dos conselheiros: "No setor médico, conforme as reclamações dos idosos precisariam ter agendamentos mais rápidos de consultas, geriatras, uma vez que é muito difícil contar com esses especialistas" (conselheira de 60 anos, ensino superior, secretaria da cultura).

Os conteúdos da classe 3 ainda apontam que há alguns desafios para serem superados pelo CMDI, implicados com a efetivação da garantia dos direitos prioritários dos idosos. $\mathrm{O}$ trecho a seguir apresenta esta questão: "O maior desafio é conseguir articular, as diversas secretarias, pois é muito complicado mostrar que é importante olhar para o idoso, como por exemplo, nos transportes, nós quase não temos ônibus adaptados aqui" (conselheira de 30 anos, ensino superior, assistência social).

"Recursos financeiros" (Classe 4): representa $15,43 \%$ dos ST retidos para análise $(\mathrm{N}=77)$. Corresponde principalmente aos depoimentos de conselheiros de 40 anos, divorciados com ensino superior completo, representantes de órgãos públicos na área de Psicologia. Os conteúdos que compõem esta classe destacam a importância do Fundo do CMDI para a construção de ações para o público idoso. O trecho seguinte apresenta como funciona o sistema de elaboração para captação de recursos: "Existe uma campanha elaborada pela comissão que eu pertenço, para nos valer de parte do imposto de renda retido, ofertados por pessoas físicas que estão na economia ativa, em favor do fundo municipal do idoso" (conselheiro de 60 anos, ensino superior, Secretaria de esportes).

O depoimento anterior, diz respeito a um contexto que ainda não foi instituído o Fundo Municipal de Direitos da Pessoa Idosa. Para melhor compreensão sobre os aspectos burocráticos que podem dificultar e prolongar ou mesmo estancar a criação do fundo do idoso em alguns municípios, será apresentado ST de outro contexto: "Houve barreiras e desafios nos aspectos da própria política das leis. Tivemos que correr atrás para compreender estas leis e colocar tudo bonito no papel e conseguir montar o fundo social do idoso" (conselheira de 40 anos, ensino superior, Psicologia).

"Responsabilidade social" (Classe 5): representa $17,03 \%$ dos ST retidos para análise $(\mathrm{N}=85)$. Corresponde principalmente aos depoimentos de conselheiros de 20 anos, divorciados com ensino superior 
completo, representantes das de gerontologia e jurídica. Os conteúdos que compõem esta classe atribuem a efetivação da garantia dos direitos dos idosos como uma responsabilidade social. Neste contexto, o papel do conselheiro é vinculado a esta responsabilidade social, como pode ser observado no trecho a seguir: "O conselheiro precisa ter consciência que futuramente ele será idoso. Assim, seu papel é ter responsabilidade de estar construindo para os idosos do município, algo para o futuro ou mesmo para o presente" (conselheira de 50 anos, ensino superior, assistência social).

Esta responsabilidade social é estendida para a sociedade civil como um todo, bem como para os órgãos públicos, como pode se perceber no trecho a seguir: "O município está dando um suporte legal para poder expandir e melhorar os serviços dentro das questões do idoso. A questão maior é a aproximação da sociedade junto com os órgãos públicos" (conselheira de 30 anos, ensino superior, área jurídica). Por outro lado, o poder público também é responsabilizado por garantir os direitos dos idosos, como pode ser observado no ST seguinte: "O desafio é a falta de consciência do poder público de que tem que ter investimento para melhorar as condições do idoso. $\mathrm{O}$ idoso é um protagonista da família e não pode estar numa margem de esquecimento" (conselheira de 40 anos, ensino superior, assistência social).

\section{Discussão}

O presente estudo identificou que a preocupação dos conselheiros com o público idoso está direcionada com as principais necessidades enfrentadas. Estas necessidades dizem respeito à falta de orientação que direcione o público idoso, para órgãos que atendam as suas necessidades imediatas, e ainda aponta a preocupação da violação dos direitos dos idosos. Abric (2001) esclarece que a função da orientação é conduzir os comportamentos e as ações dos indivíduos, sendo um guia para ação orientando como o indivíduo ou grupo representa a realidade. $\mathrm{E}$ como a função cognitiva das representações sociais é de familiarizar novas informações, a prática de orientar e direcionar os idosos sobre como proceder para amenizar ou solucionar os seus problemas, seria uma estratégia para possibilitar a retenção, seleção e interpretação da informação fornecida. Brown (1999) ressalta a importância de orientar e conscientizar os idosos sobre os modos de procedimentos e prevenções contra doenças incapacitantes. De tal modo, o comportamento de direciona-los a se situarem ao sistema de normas inclusos na sociedade, poderia contribuir para capacidade de modificação dos seus desempenhos cognitivo e social.

Em relação à violação dos direitos dos idosos, os depoimentos apontam que os conflitos familiares apresentam indícios de abusos que os fragilizam e isolam do convívio social. Estes resultados corroboram com pesquisa que identificou a existência de conflitos familiares nos discursos de idosos (Fernandes \& Andrade, 2016). Por outro lado, as representações sociais identificadas não são causas do comportamento dos familiares. Elas são diretrizes para compreender este comportamento social. Portanto, não se deve estabelecer o modelo de causalidade mecanicista e linear que relaciona representações e práticas como desencadeadoras de atitudes positivas ou negativas. As representações sociais são os modos de compreensão dos problemas da vida cotidiana, com uma função adaptativa (Morin, 2003).

Desde a época da antiguidade reconhece-se a existência de conflitos familiares que geram tensões intergeracionais (Beauvoir, 1990). Assim, compreende-se que esta realidade objetivada e cristalizada é reconstruída no sistema cognitivo que é ancorada no sistema de valores, no contexto sócio histórico e ideológico (Moscovici, 2012). Nota-se que atualmente este cenário não se modificou, uma vez que em várias reuniões plenárias nos CMDI debatia-se a questão da violência contra o idoso no ambiente familiar. A literatura nacional também aponta o enfrentamento da violência contra idoso fato recorrente no Brasil (Fonseca \& Gonçalves, 2003; Souza \& Minayo, 2010; Moreira et al., 2016). Para que esta uma imagem objetivada ser reconstruída cognitivamente prediz a necessidade de uma flexibilidade, para aceitação, e respectivamente inserção de novas ideias positivas ancoradas em diferentes valores, crenças ou atitudes perante o público idoso (Moscovici, 2012).

Quando se fala no termo violência significa toda e qualquer forma de agressão ou negligência física, psíquica ou social (Muller \& Parada, 2013; Moreira et al., 2016). Neste sentido, o abuso financeiro além de também ser um tipo de violência, foi uma das ações mais citadas nos discursos sobre violência contra o idoso. Camacho e Coelho (2010) apontam que mesmo sem haver uma capacitação para a função, a responsabilidade pelos cuidados com os idosos vem sendo 
direcionada à família. Assim, o poder que a família exerce sobre o idoso em condições de fragilidade física ou psíquica, lhes oferece o controle de seus rendimentos ou benefícios previdenciários financeiros. Fonseca e Gonçalves (2003) ressaltam que o descaso do poder público com a saúde psicológica dos idosos e da família favorece os conflitos, induz a fragilidade dos laços familiares e a ocorrência de violência intrafamiliar. Vale ressaltar que a determinação da conduta do indivíduo ou grupo provavelmente será orientada conforme os ditames de princípios que lhe são familiares, mesmo quando estes ditam conduta controvérsia.

Outras violações dos direitos dos idosos que preocupam principalmente os conselheiros viúvos e que se encontram da fase da velhice referem-se às áreas da saúde e do transporte público. Flament, Guimelli \& Abric (2006), explicam que os indivíduos enfrentam pressões sociais mais ou menos graves, dependendo do nível de sensibilidade para com objeto da representação. Apesar das medidas de proteção aos idosos terem contemplado o direito à saúde na estruturação e estabelecimento de políticas públicas de favorecimento a população idosa, nos âmbitos internacionais e nacionais (Muller \& Parada, 2013; Organização das Nações Unidas [ONU], 2014), a rede de proteção dos direitos da pessoa idosa na área da saúde ainda precisa se fortalecida (Souza \& Minayo, 2010). Logo, as representações que estes conselheiros apresentam sobre o conselho municipal do idoso são influenciadas pelo processo do qual este objeto e o próprio idoso é representado.

Por outro lado, a identidade dos princípios de regulação não impede de forma alguma a diversidade de posições em relação ao público idoso (Doise, 2002). Embora os avanços científicos não possibilitassem uma velhice sem perdas, o processo de envelhecimento bem-sucedido implica a ideia da adoção de comportamentos de promoção da saúde para chegar à fase da velhice apresentando boa energia física decorrente da conservação da saúde (Martin et al., 2015). No cenário internacional estudos discutem ações preventivas e interventivas, com o apoio de investimentos financeiros e da tecnologia, para promover a qualidade da saúde e dos serviços de transporte, e assim garantir os direitos dos idosos (Torrado Ramos et al., 2014; Song \& Chen, 2015). Neste sentido, o estudo das representações sociais permite compreender os processos envolvidos na adaptação e perspectivas dos indivíduos ou grupos à realidade atual, conforme as características de seu ambiente social e ideológico.
Os conflitos com o transporte público é outro elemento marcante nos discursos destes conselheiros, pois a falta de sensibilização da sociedade para com as dificuldades de mobilidade física e o descaso das companhias de transporte público em atender este segmento é uma das principais queixas. Moscovici (2012) explica que um dos componentes da representação social é a atitude do indivíduo ou grupo frente ao objeto, e esta atitude não pode ser considerada como sinônimo de comportamento, pois reside na natureza avaliativa deste objeto. Conforme Wasfi, Levinson e El-Geneidy (2012) o objetivo dos sistemas de transporte público está direcionado para a promoção da acessibilidade e mobilidade da comunidade como um todo. Porém, a avaliação negativa frente ao idoso orienta a atitudes e ações desfavoráveis perante este público (Moscovici, 2012). Logo, os idosos deveriam ser incluídos, neste contexto, mas as necessidades especiais provenientes das limitações que muitos possuem geram transtornos e desconfortos em comparação com os passageiros regulares.

Neste cenário, de violação dos direitos da pessoa idosa, os conselheiros participantes da pesquisa atribuem ao público civil, incluindo os próprios idosos, a responsabilidade de proteção destes direitos. E ainda, culpabilizam as falhas do atendimento público do município de serem negligentes com os cuidados com a pessoa idosa, e consequentemente desrespeitam-se as legislações que estabelecem os seus direitos. Vale lembrar, que a negligência também é um ato de violência e o Estatuto do Idoso oferece proteção para a população idosa contra a negligência, discriminação, violência e opressão (Brasil, 2012; Souza \& Minayo, 2010). Logo, é pertinente a compreensão do papel do conselheiro do CMDI no planejamento e defesa das políticas públicas para a população idosa.

A dinâmica do CMDI é regulada pelas condições estabelecidas para a atuação dos conselheiros, ou seja, a impossibilidade de exercerem a função de conselheiro de modo exclusivo. Eles trabalham nos órgãos públicos, privados ou ONG e são indicados por suas respectivas secretarias ou departamentos para desempenharem o papel de conselheiros, como representantes dos órgãos que são vinculados (Muller \& Parada, 2013). Logo, o desempenho de suas funções é voluntário e este comportamento pró-social pode ser desenvolvido com objetivo de favorecer o público idoso, pois o altruísta não mede esforços para ajudar o próximo, sem esperar algo em troca. Suas motiva- 
ções são intrínsecas com consequências sociais positivas, mesmo que este ato envolva algum custo para si (Rodrigues, Leal, \& Jablonski, 2009). Porém, certas normas sociais, muitas vezes prescrevem o comportamento apropriado dos indivíduos em determinadas situações, os orientando quanto e como devem agir quando alguém precisa de ajuda. Neste sentido, a ocupação primordial e remunerada dos conselheiros, diz respeito ao órgão de origem, e assim a presença e atuação no CMDI dependem da disponibilidade destes atores que precisam atender primeiramente as demandas de seus respectivos trabalhos.

As reuniões plenárias e de comissões específicas recorrentes no CMDI têm o objetivo de avaliar reais necessidades dos idosos, para ser possível a discussão de novas diretrizes que promovam a elaboração de planos de ação, que busquem solucionar os problemas existentes município. No entanto, foi identificada a necessidade de fomentarem-se motivações extrínsecas para trazer os conselheiros nestas reuniões, para o compartilhamento de ideias e, consequentemente a produção de novos sentidos que orientem comumente as suas ações em prol do público idoso (Wagner, 2015). A carência de representantes idosos para apoiar a causa é citada, uma vez que foi cobrada a responsabilidade dos idosos em condições ativas contra a violação dos seus direitos, como também foi observada à falta de interesse destes nas reuniões.

A divulgação da existência do CMDI é apontada nos depoimentos como essencial para participação ativa da sociedade na defesa, promoção e elaboração de políticas públicas para a população idosa. A PNI declara que o processo de envelhecimento diz respeito à sociedade em geral, e deve ser objeto de conhecimento e informação para todos (Muller \& Parada, 2013). Assim, compreende-se que a divulgação da informação perpassa a simples emissão do conteúdo a ser transmitido, pois proporciona o poder de persuasão e/ou do avanço do conhecimento.

As diretrizes para atuação dos conselheiros do CMDI estão pautadas nas prioridades de atendimento ao idoso: saúde, educação, transporte e habitação. Para a elaboração destas diretrizes os conselheiros enfrentam o desafio de tentar articular saberes e experiências intersetoriais. Logo, buscam a intersetorialidade para possibilitar a inclusão social dos idosos e a proteção dos seus direitos (Leandro-França \& Giardini Murta, 2014; Oliveira, Ramos, Panhoca, \& Santos Alves, 2014). É interessante notar que tais direi- tos prioritários para estes conselheiros, também são citados no Estatuto do Idoso (Brasil, 2012). Neste sentido, é possível inferir que estes conselheiros também se apoiam nas legislações vigentes para orientar o planejamento de suas ações.

Para o cumprimento das diretrizes que buscam a garantia de direitos dos idosos, os conselheiros contam com o apoio da doação de recursos financeiros. Novamente, percebe-se que os conselheiros estão conectados com as legislações vigentes e atuais, uma vez que a $4^{\text {a }}$ Conferência Nacional dos Direitos da Pessoa Idosa estabeleceu ser competência do CMDI, a captação de recursos financeiros, além de acompanhar e controlar o Fundo Municipal do Idoso (Brasil, 2016). Por fim, os conselheiros estendem a obrigação de garantir os direitos dos idosos como uma responsabilidade social. Logo, cabe a aproximação da sociedade junto aos órgãos públicos, sendo de competência do poder público, a conscientização da necessidade de investimentos financeiros na causa dos idosos, e para os conselheiros do CMDI resta o papel de identificar-se e lutar pela causa dos idosos com um olhar construtivo e prospectivo.

\section{Considerações finais}

O presente estudo apresentou fatores que podem implicar nos planejamentos de políticas públicas para população idosa, por meio da compreensão do contexto de atuação dos conselheiros municipais do idoso. A preocupação dos conselheiros em relação aos idosos do município, diz respeito às necessidades de encaminhar os idosos para medidas de cuidados protetivos, e por consequência protegê-los de situações conflitantes que violem os seus direitos. As violações de direitos mais citadas pelos conselheiros ocorrem no ambiente familiar e nas áreas da saúde e do transporte público. Neste cenário, eles atribuem à sociedade civil e ao poder público municipal a responsabilidade de garantir os direitos dos idosos. E como os CMDI possuem representantes de ambos os segmentos, as representações sociais destes conselheiros apresentam ineficácia destes órgãos na garantia dos direitos dos idosos.

Conforme a análise dos discursos dos conselheiros, a dinâmica de ações desenvolvida no CMDI é regida pelas motivações e dificuldades que são discutidas em reuniões recorrentes. Logo, também ponderam sobre as prioridades para o atendimento do público idoso (saúde, educação, transporte e habitação). Para o 
desenvolvimento destas ações que garantam os direitos dos idosos precisam do apoio de recursos financeiros (fundo municipal do idoso) e da responsabilidade social dos conselheiros, da sociedade civil e do poder público. Vale ressaltar, que a dificuldade diversas vezes apontada no discurso dos conselheiros, diz respeito à impossibilidade de exercerem suas funções no CMDI de modo exclusivo, por possuírem outras atribuições nos seus locais de trabalho de origem. Ainda apontam a necessidade de divulgação do CMDI e do desenvolvimento de reuniões mais atrativas.

Concluindo, pode-se afirmar que apesar dos conselheiros do CMDI terem como função fiscalizar e regularizar políticas públicas efetivas para a população idosa, eles deparam-se com dificuldades para exercer plenamente a função de conselheiro. Vale ressaltar, que muitos destes atores estão envolvidos diretamente ou indiretamente no meio político, o que pode os induzir a responder aquilo que é normativamente correto. Logo, torna-se complexo identificar nitidamente suas perspectivas de planejamentos de políticas públicas para população idosa.

De qualquer modo, estes atores contribuíram a partir dos discursos de suas práticas sociais dentro do conselho, com informações para melhor compreensão das dificuldades encontradas por este público para garantir os direitos do público idoso. Portanto, sugere-se o delineamento de pesquisas que aprofundem o tema proposto, uma vez que os conselheiros são atores fundamentais para efetivar as legislações vigentes que garantem os direitos dos idosos.

\section{Referências}

Abric, J. C. (2001). O estudo experimental das representações sociais. In D. Jodelet (Org), As representações sociais (pp. 155-171). Rio de Janeiro, RJ: UERJ.

Almeida, A. M. O., Santos, M. F. S., \& Trindade, Z. A. (2000). Representações e práticas sociais: Contribuições teóricas e dificuldades metodológicas. Temas em psicologia, 8(3), 257-267.

Atlas Brasil. (2013). Índice de desenvolvimento humano municipal brasileiro. Brasília, DF: PNUD. Recuperado de: http://www.atlasbrasil.org.br/2013/

Beauvoir, S. (1990). A velhice (M. H. F. Monteiro, Trad.). Rio de Janeiro, RJ: Nova Fronteira.

Brasil. Ministério da Saúde. (2012). Estatuto do idoso (3a ed.). Brasília, DF: o autor.

Brasil. Ministério da Justiça e Cidadania. (2016). Conferência conjunta de direitos humanos: 4 Conferência Nacional de Direitos da Pessoa Idosa. Brasília, DF: o autor. Recuperado de http://www.sdh.gov.br/assuntos/conferencias$\mathrm{dh} / 4 \mathrm{a}$-conferencia-nacional-dos-direitos-da-pessoa-idosa

Brown, D. K. (1999). A context for teaching aging-related public policy. Educational Gerontology, 25(8), 711-722. https://doi.org/10.1080/036012799267459

Camacho, A. C. L. F., \& Coelho, M. J. (2010). Políticas públicas para a saúde do idoso: Revisão sistemática. Revista Brasileira de Enfermagem, 63(2), 279-284. https://doi.org/10.1590/S0034-71672010000200017

Camargo, B. V., \& Justo, A. M. (2013). IRAMUTEQ: Um software gratuito para análise de dados textuais. Temas em Psicologia, 21(2), 513-518. https://doi.org/10.9788/TP2013.2-16

Doise, W. (2002). Da psicologia social à psicologia societal. Psicologia Teoria e Pesquisa, 18(1), 27-35. https://doi.org/10.1590/S0102-37722002000100004

Fernandes, J. S. G., \& Andrade, M. S. (2016). Representações sociais de idosos sobre velhice. Arquivos Brasileiros de Psicologia, 68(2), 48-59.

Flament, C., Guimelli, C., \& Abric, J. C. (2006). Effets de masquage dans l'expression d'une représentation sociale. Les Cahiers Internationaux de Psychologie Sociale, 1(69), 15-31. https:// doi.org/10.3917/cips.069.0015

Fonseca, M. M. \& Gonçalves, H. S. (2003). Violência contra o idoso: Suportes legais para a intervenção. Interação em Psicologia, 7(2), 121-128. https://doi.org/10.5380/psi.v7i2.3230

Global AgeWatch Index. (2013). Insight report. London: o autor. Recuperado de: http://www.helpage.org/global-agewatch/reports/global-agewatch-index-2013-insight-report-summary-and-methodology.

Instituto Brasileiro de Geografia e Estatística - IBGE. (2013). Síntese dos indicadores sociais 2013: Uma análise das condições de vida da população brasileira. Rio de Janeiro, RJ: o autor. Recuperado de: http://www.ibge.gov.br. 
Leandro-França, C., \& Giardini Murta, S. (2014). Prevenção e promoção da saúde mental no envelhecimento: Conceitos e intervenções. Psicologia: Ciência e Profissão, 34(2), 318-329. https:// doi.org/10.1590/1982-3703001152013

Martin, P., Kelly, N., Kahana, B., Kahana, E., Willcox, B. J., Willcox, D. C. et al. (2015). Defining successful aging: A tangible or elusive concept? The Gerontologist, 55(1), 14-25. https://doi.org/10.1093/geront/gnu044

Moreira, W. C., Damasceno, C. K. C. S., Vieira, S. K. S. F., Campêlo, T. P. T., Campêlo, D. S., \& Alencar, D. D. C. (2016). Análise sobre as políticas públicas de enfrentamento a violência contra o idoso. Revista de Enfermagem UFPE on line, 10(4), 1324-1331. https://doi.org/10.5205/reuol.8464-74011-1-SM.1004201621

Morin, M. (2003). Entre representaciones y prácticas: El SIDA, la prevención y los jóvenes. In J. C. Abric (Org.), Prácticas sociales y representaciones (pp. 97-128). México, DF: Coyoacán.

Moscovici, S. (2012). Representações sociais: Investigações em psicologia social. Petrópolis, RJ: Vozes.

Muller, N. P., \& Parada, A. (Orgs.). (2013). Dez anos do conselho nacional dos direitos dos idosos: Repertórios e implicações de um processo democrático. Brasília, DF: Secretaria de Direitos Humanos.

Oliveira, A. D., Ramos, O. A., Panhoca, I., \& Alves, V. L. S. (2014). A intersetorialidade nas políticas públicas para o envelhecimento no Brasil. Kairós Gerontologia, 17(2), 91-103.

Organização das Nações Unidas - ONU. (2014). Envelhecimento. Brasília, DF: Centro Regional de Informações das Nações Unidas. Recuperado de: https://www.unric.org/pt/envelhecimento.

Rodrigues, A., Leal, E. M., \& Jablonski, A. B. (2009). Psicologia social (27a ed. rev. amp.). Petrópolis, RJ: Vozes.

Song, P., \& Chen, Y. (2015). Public policy response, aging in place, and big data platforms: Creating an effective collaborative system to cope with aging of the population. Bioscience Trends, 9(1), 1-6. https://doi.org/10.5582/bst.2015.01025

Souza, E. R., \& Minayo, M. C. S. (2010). Inserção do tema violência contra a pessoa idosa nas políticas públicas de atenção à saúde no Brasil. Ciência \& Saúde Coletiva, 15(6), 2659-2668. https://doi.org/10.1590/S1413-81232010000600002

Torrado Ramos, A. M., Sánchez Pérez, L., Somonte López, R., Cabrera Marsden, A. M., Pino Santos, P. C. H., \& Lorenzo Pérez, O. (2014). Envejecimiento poblacional: Una mirada desde los programas y políticas públicas de América Latina, Europa y Asia. Revista Novedades en Población, 10(19), 18-29.

Wagner, W. (2015). Representation in action. In G. Sammut, E. Andreouli, G. Gaskell, \& J. Valsiner (Eds.), The Cambridge handbook of social representations (pp. 12-28). Cambridge: Cambridge University.

Walker, A. (2002). A strategy for active ageing. International Social Security Review, 55(1), 121-139. https://doi.org/10.1111/1468-246X.00118.

Wasfi, R., Levinson, D., El-Geneidy, A. (2012). Measuring the transportation needs of seniors. Journal of Transport Literature, 6(2), 8-32. https://doi.org/10.1590/S2238-10312012000200002

Xavier, R. (2002). Representação social e ideologia: Conceitos intercambiáveis? Psicologia \& Sociedade, 14(2), 18-47. https://doi.org/10.1590/S0102-71822002000200003

Janaína da Silva Gonçalves Fernandes

Doutora e Mestre em Psicologia Educacional. Professora do Programa dePós-Graduação em Psicologia Educacional Centro Universitário FIEO (Unifieo), Osasco - SP. Brasil.

E-mail: janaina.fernandes@unifieo.br

(iD) https:// orcid.org/0000-0001-6621-9185

\section{Márcia Siqueira de Andrade}

Doutora e Mestre em Psicologia da Educação. Coordenadora do Programa de Pós-Graduação em Psicologia Educacional do Centro Universitário FIEO (Unifieo), Osasco - SP. Brasil.

E-mail:mandrade@unifieo.br

(iD https:// orcid.org/0000-0002-0998-0143 
Psicologia: Ciência e Profissão 2019 v. 39, e187297,1-14.

Endereço para envio de correspondência:

Avenida Franz Voegeli, 300, Vila Yara. CEP: 06020-190. Osasco - SP. Brasil.

Recebido 31/10/2017

Reformulado 26/06/2018

Aceito 23/08/2018

Received 10/31/2017

Reformulated $06 / 26 / 2018$

Approved 08/23/2018

Recibido 31/10/2017

Reformulado 26/06/2018

Aceptado 23/08/2018

Como citar: Fernandes, J. S. G.; Andrade, M. S. (2019). Conselhos Municipais do Idoso e representações sociais de seus conselheiros. Psicologia: Ciência e Profissão, 39, 1-14. https://doi.org/10.1590/1982-3703003187297

How to cite: Fernandes, J. S. G.; Andrade, M. S. (2019). Municipal Councils of the Elderly and social representations of their counselors. Psicologia: Ciência e Profissão, 39, 1-14. https://doi.org/10.1590/1982-3703003187297

Cómo citar: Fernandes, J. S. G.; Andrade, M. S. (2019). Consejos Municipales de las Personas Mayores y representaciones sociales de sus consejeros. Psicologia: Ciência e Profissão, 39, 1-14. https://doi.org/10.1590/1982-3703003187297 